\title{
Fingerling production and stock enhancement of Mahisefid (Rutilus frisii kutum) lessons for others in the south of Caspian Sea.
}

\begin{abstract}
Rutilus frisii kutum (Kamensky 1901) is one of the economically important fishes that migrate for spawning to rivers in the Caspian Sea. However, the fish populations have slowly decreased in recent years. The declining of these resources has resulted from some activities by the Iranian Fisheries Organization (IFO is responsible for stock enhancement) to catch some broodstocks of Rutilus frisii kutum from their natural spawning rivers. The broodstocks are caught for artificial propagation of the fish. Artificial propagations are carried out every year to produce fingerlings to be released into the rivers in the Caspian Sea. In recent years, total catch of this fish have greatly fluctuated due to the disruption of the natural spawning grounds and over fishing. The substantial reduction to 1,298 metric tons, the lowest total catch reported in 1984-1985, could be due to over-exploitation of the fishery resources. However, the total catch has increased after the fingerlings release programs started in 1979. The total numbers of Rutilus frisii kutum fingerlings released had increased from 12 million to 225 million in 2002, to 155 million pieces in 2003, to 179 million pieces in 2004, 229 million pieces in 2005, 174 million pieces in 2006, 262 million pieces in 2007 and 187.1 in 2008. The total catch was also increased from 6,417 metric ton to 8,984 metric ton, to 7,036 metric ton, to 9,631 metric ton and $16,117,17,196,14,835$ in years $2002,2003,2004,2005$, 2006, 2007 and 2008, respectively.
\end{abstract}

Keyword: Fingerling production; Stock enhancement; Mahisefid (Rutilus frisii kutum); Caspian Sea. 